REVIEW

\title{
The adolescent with a chronic condition. Part I: developmental issues
}

\author{
J-C Suris, P-A Michaud, R Viner
}

Arch Dis Child 2004;89:938-942. doi: 10.1136/adc.2003.045369

The prevalence of chronic conditions among adolescents is difficult to assess due to the lack of quality data focusing specifically on this age group, as well as the diversity in methodology and definitions used. However, surveys carried out by self administered questionnaires among inschool adolescent populations indicate that around $10 \%$ of adolescents suffer from such a condition. The aim of this paper is to analyse the reciprocal effects of chronic conditions and adolescent development by reviewing the effect of chronic disease on growth and puberty and on psychosocial development, and the effect of developmental issues on the course and management of chronic disease.

See end of article for authors' affiliations

Correspondence to Dr J-C Surís, GRSA/ IUMSP, Bugnon, 17, 1005

Lausanne, Switzerland; joan-carles.suris@ hospvd.ch

Accepted 6 February 2004
A 2001 the Department of Child and Adolescent Health of the World Health Organisation (WHO) asked the authors to write a review and discussion paper on the clinical management of chronic conditions in adolescents (Obligation no. HQ/01/407101). After agreeing on the outline of the main topics to be discussed, the authors sought for the most relevant literature in the field, focusing whenever possible on evidence based papers. For this purpose on-line database searches (including Medline, Embase, and PsycINFO) and relevant grey literature were used. The present paper is the first of a two part shorter version of the WHO manuscript.

\section{EPIDEMIOLOGY}

The prevalence of chronic conditions among adolescents is difficult to assess due to the lack of quality data focusing specifically on this age group, as well as the diversity in methodology and definitions used. ${ }^{12}$ There are many issues involved in the definition of chronic health conditions, including duration, age of onset, whether it is congenital or acquired, limitation of age appropriate activity, visibility, expected survival, mobility, physiological functioning, cognition, emotional/social impairment, sensory functioning, communication impairment, course, and uncertainty. ${ }^{3}$ If conditions such as mild asthma or correctable vision conditions are included in the definition, the prevalence rate for chronic conditions in adolescence can be as high as $15 \%$. If the definition is narrowed, the prevalence is reduced by half. ${ }^{4}$

Raw data regarding the prevalence of chronic conditions among in-school adolescents according to surveys carried out by self administered questionnaires in France, Switzerland, and Canada $^{5-7}$ indicate that around $10 \%$ of adolescents suffer such a condition. Note that the validity of these data is limited as school based surveys may not include those with severe physical or mental limitations who either stay at home or live in special institutions. Globally, rates seem to be higher among males, among rural residents, among less privileged social classes, among impoverished areas within countries, and among adolescents living in less educated families. ${ }^{18}$

The management of any chronic condition during adolescence, a time of rapid growth and physiological changes accompanied by important individuation and socialisation processes, constitutes a major challenge for the individual, his/ her family, and the healthcare team. The purpose of this paper is to review the impact of chronic conditions on the bio-psychosocial processes of adolescence.

For this purpose, a non-categorical approach has been used, as defined by Stein and Jessop. ${ }^{910}$ These authors suggest that there are commonalties that cross disease categories and that, while there are issues that are specific to each disease, the commonalties can be used to increase the experience of the practitioner. These crossdisease commonalties apply not only to children and adolescents, but also to their families. ${ }^{3}$ Finally, although this paper focuses mainly on the issue of somatic diseases, its content does apply to a large extent to any chronic condition, including mental illness and chronic disability.

\section{THE RECIPROCAL EFFECTS OF CHRONIC CONDITION AND ADOLESCENT DEVELOPMENT}

The development of the individual during this period of life can be divided into three main stages: early, middle, and late adolescence, each characterised by specific biological, psychological, and social steps. While any chronic condition can potentially affect these developmental processes, the reverse is true-that is, both physiological change and psychosocial adjustments can have an impact on the disease (table 1).

\section{Effect of chronic disease on growth and puberty}

Delayed growth and puberty is common to most chronic illnesses, although more frequent in those where malnutrition and chronic inflammation are most common (for example, bowel disorders, cystic fibrosis). This delay may be transient, with later catch-up growth producing normal adult heights, although permanent 
Table 1 Reciprocal effects of chronic illness or disability and adolescent development ${ }^{68-72}$

Effects of chronic illness or disab
Biological
Delayed/impaired puberty
Short stature
Reduced bone mass accretion
Psychological
Infantilisation

Adoption of sick role as personal identifier Egocentricity persists into late adolescence Impaired development of sense of sexual or attractive self Impaired development of cognitive functions and information processing

Social

Reduced independence at a time of when independence is normally developing Failure of peer relationships then intimate (couple) relationships Social isolation

Educational failure and then vocational failure; failure of development of independent living ability
Effects of developmental issues on chronic illness or disability

Biologically

Increased caloric requirement for growth may negatively impact on disease parameters

Pubertal hormones may impact on disease parameters (e.g. growth hormone impairs metabolic control in diabetes)

Poor adherence and poor disease control due to:

Poorly developed abstract thinking and planning (reduced ability to plan and prepare using abstract concepts)

Difficulty in imagining the future; self-concept as being "bullet proof"

Rejection of medical professionals as part of separation from parents Exploratory (risk taking) behaviours

Associated health risk behaviours

Chaotic eating habits may result in poor nutrition

Smoking, alcohol and drug use often in excess of normal population rates

Sexual risk taking, possibly in view of realisation of limited life span

-

growth loss may also occur. Large birth cohort studies such as the British 1958 birth cohort of 12537 subjects found that physical chronic illness of any type in childhood and adolescence made no difference to adult height, whereas children with psychosocial chronic illnesses (for example, enuresis, mental health problems) were $1 \mathrm{~cm}$ shorter as adolescents and adults, a finding which remained significant when controlling for confounders such as socioeconomic status. ${ }^{11}$

Biological, psychological, and social development are highly inter-related and the timing of one may affect development in other domains. The psychological and social effects of delayed puberty should not be ignored. Delayed puberty may result in low self-esteem in boys and in difficulty in separating from parents due to apparent immaturity. Adolescents affected by delayed puberty may be treated as less mature than real age by adults and peers, and face difficulties in getting work due to apparent immaturity. ${ }^{12}$

\section{Effect of chronic disease on psychosocial development Wellbeing and mental health}

The wellbeing of chronically ill adolescents is determined largely by the severity of the disease and the amount of treatment required, however it is also determined by the psychological and social complications that may accompany such conditions. ${ }^{13}$ The variable nature of such complications is shown in the sometimes contradictory findings in different studies: in a meta-analysis review, Lavigne and FaierRoutman $^{14}$ found that the risk of psychological adjustment problems can vary across disease groups-young people with chronic conditions are likely to display internalising symptoms than healthy controls. Other studies ${ }^{15}$ found that chronically ill girls were more likely to have emotional problems than their healthy counterparts, but that the same was not true for boys. Ill adolescents are more likely to develop psychiatric and behavioural disorders, ${ }^{16}$ may show a higher prevalence of at least one psychiatric diagnosis than healthy controls, ${ }^{17}$ and are more likely to be depressed or have low self-esteem. ${ }^{18}$ In type 1 diabetes, young adults appear to be as psychologically well adjusted as their healthy peers, ${ }^{19}$ whereas young people with asthma appear to feel lonely, unhappy, or depressed and suffer from somatic symptoms significantly more often than healthy controls. ${ }^{20}$

\section{Cognitive capacities}

With the exception of most inherited metabolic diseases, it is unlikely that chronic illness affects the basic neuronal maturational mechanisms that underlie the development of abstract thinking capabilities in adolescence, although little data exists on this area. Certain chronic illnesses such as diabetes and sickle cell disease are known to have long term neuropsychological effects in adolescence, although these are the result of the disease process (hypoglycaemia in diabetes ${ }^{21}$ and cerebrovascular accidents in sickle disease $\mathrm{e}^{22}$ ) rather than representing a generic chronic illness effect.

In contrast, there is evidence that identity, self-image, and ego-development are affected by chronic illnesses in a generic fashion. ${ }^{23}$ This is particularly true when illness is more severe and verbal IQ is higher. ${ }^{24}$ Body image and the development of a sense of the sexual sense may also be impaired by chronic illnesses which either distort the physical body (for example, stomas or scars $)^{25}$ or require treatments that may be distancing to others. ${ }^{26}$ Population based studies show that adolescents with chronic illness report higher body dissatisfaction than adolescents without chronic illness. These body image issues focus particularly on weight and result in higher rates of high risk weight loss practices. ${ }^{27}$ Body image issues or dissatisfaction may theoretically impair later sexual function, although population based studies suggest that adolescents with chronic illness have higher rates of sexual intercourse and unsafe sexual practices than healthy controls. ${ }^{28}$ It is possible that body image problems may act to increase risk in sexual behaviour.

\section{Education and school}

The issue of school health should be tackled from a broad perspective..$^{29}{ }^{30}$ The first question that arises is related to the information that is given to the school health staff (if existing) and to the teachers and classmates. For understandable reasons, many parents and teenagers are reluctant to disclose some conditions, with the fear that they may become labelled and stigmatised. More commonly, young people, from an understandable wish not to stand out, do not communicate any information on their disease, which may lead to the development of a crisis situation within the school (diabetic coma, cardiac failure, severe asthma attack, etc). Both the parents and the teenagers should be strongly encouraged to disclose information in an appropriate and stepwise manner: the school health nurse or physician should 
be fully notified of the situation, whereas the briefing to the teaching staff should be restricted to those pieces of information which they have to know to support the pupil or to cope with critical events. ${ }^{29}{ }^{31}$ This process should be as open as possible and run with the consent, and if possible with the assistance, of the patient. In a regular fashion, information should be exchanged between the healthcare team, the school health staff, and the teachers.

Recurrent illness and the demands of treatment regimens may significantly impact on school attendance and educational achievement, which in turn may result in vocational impairments and loss of financial independence in adult life. Additionally, the developmental imperative for educational attainment may affect chronic illness through conflicts of priorities between chronic illness management and schooling requirements. Young people and their families may prioritise education over treatment during the key educational stages in later adolescence; for example, missed appointments, refusal to do lunchtime treatments, or refusal of regular transfusions in sickle cell disease due to missed school. ${ }^{32}$ The way that health professionals deal with the educational system is key in reducing the impact of intensive educational requirements on chronic illness management. ${ }^{31}{ }^{33}$

Teenagers with chronic conditions are more likely than their healthy peers to miss school due to their condition or to the treatment they need. ${ }^{34}$ School attendance may be affected by the severity of the illness, treatment adherence, and psychological problems, ${ }^{32}$ but ill young people miss more school days both due to their health problems and because they are more likely to skip school. ${ }^{7}$ In fact, adolescents with chronic conditions often miss more school days than can be attributed to their treatment needs. ${ }^{35}$ Lost school time ranges from $13 \%$ for patients with orthopaedic problems to $35 \%$ for those with cancer. ${ }^{35}$ Evidence from studies of adolescents with chronic arthritis also shows significantly higher school absence than the general population, and that school absence is associated with decreased compliance with physical treatments and with psychological disturbance. ${ }^{32}$

The issue of absenteeism is of particular relevance: severe chronic conditions often induce frequent hospitalisations and the healthcare team should try to link with specialised inhospital teachers or establish cooperation with teachers or classmates to allow the patient to cope with the schooling programme. ${ }^{30}$ In rare instances, it may be more appropriate to educate some young people in special facilities. However, to avoid discrimination as much as possible, every effort should be made to integrate adolescents with a chronic conditionincluding those with physical disabilities-into a normal school environment.

The question is to what extent do such educational difficulties have a long term impact? Data from the longitudinal British 1958 birth cohort show that chronic illness in childhood/adolescence resulted in poorer educational qualifications and higher risk of unemployment, particularly in males. ${ }^{36}$ However, adolescents with chronic illness followed up into middle age showed no diminution of financial outcomes, except in those from lower socioeconomic classes who had significantly lower life chances and income. ${ }^{37}$ This suggests that the deleterious effects of chronic illness on educational and vocational outcomes may be overcome by higher family and professional support. In the clinical arena, the importance of actively helping young people with chronic illness or disability develop independent adult living and vocational skills has been shown in longitudinal follow up studies. $^{38}$

\section{Family and peer relations}

The presence of an adolescent with a chronic condition imposes an increased burden on the parents: ${ }^{39}$ the demands of managing a chronic illness and the restrictions on lifestyle inherent in many disabling conditions increase dependence on the family and carers at a time when this should be decreasing. ${ }^{40}$ At the same time, young people may also become excluded from their peer group, particularly in those with taxing medical conditions and those that mark them out as very different (for example, ileostomy). ${ }^{25}$ Given the wide range of severity of chronic conditions as well as differences in measuring family functioning, it is once again not surprising that research findings can be conflicting: some families adequately cope with this situation while others are overwhelmed by the problems brought by the condition. Most young people with chronic conditions describe the relationship within their family as good, although their parents tend to overprotect them. ${ }^{41}$ Adolescents with cystic fibrosis reveal that family members provide tangible support. $^{42}$ While some studies found no differences in family functioning, ${ }^{39}$ others indicate that family interaction may be lower in chronically ill young people than among their healthy controls. ${ }^{43}$ Mothers of chronically ill children and adolescents may show higher levels of psychopathological symptoms, whereas fathers may not: ${ }^{44}$ mothers tend to concentrate on day to day activities and are more likely to show depressive symptoms, while fathers tend to concentrate on long range problems and are more likely to report stress. ${ }^{16}{ }^{45}$ However, according to a Finnish study, ${ }^{46}$ only $7 \%$ of interviewed parents indicated that having a child with a chronic condition had decreased parental closeness. Similarly, both a Canadian and an American ${ }^{47} 48$ study indicate that parents of children with chronic conditions are not at greater risk of marital distress or show differences in marital status compared to parents of normal children. In fact, more adaptive family relationships and parental psychological adjustment are associated with positive psychological adjustment. ${ }^{49}$ 50

One of the very best ways for any adolescent to engage in his/her individuation process is to rely on peer relationships. ${ }^{51}$ Indeed, peers provide the adolescent with support that enables them to break loose from their parents and adults in general. ${ }^{4152} 53$ Moreover, it is with peers that adolescents exchange a lot of ideas and feelings, and these encounters greatly contribute to identity formation. Adolescents with chronic conditions come as no exception to this rule, and it is thus both important and helpful to encourage all forms of socialisation.

Peer support is crucial during this period of intense socialisation, ${ }^{42}$ although the friends of adolescents with chronic illness are often younger and non-disabled. ${ }^{41}$ Many young people with chronic illnesses report having excellent peer relationships, ${ }^{54}$ and there is evidence that some illnesses (for example, cancer) may even increase peer acceptability. ${ }^{55}$

The healthcare team can promote this process in several ways, such as discussing this issue directly with both the parents and the patient, examining how the organisation and the content of the treatment can be modified according to the adolescent's lifestyle, or encouraging the young person to join informal and formal youth groups such as sports clubs, theatre and music associations, scout organisations, etc.

Self-help organisations which gather the families of individuals with specific diseases can be useful to organise special events such as conferences, outings, and tours, which promote exchanges between adolescents facing similar situations. ${ }^{56} 57$

\section{Effect of developmental issues on the course and management of chronic disease} Impact of growth and pubertal changes

Puberty and the adolescent growth spurt pose a significant caloric and metabolic burden on the healthy adolescent body, 
and may destabilise chronic illnesses. The evidence for this is clear in diabetes, where increased growth hormone levels cause insulin resistance, ${ }^{58}$ but lacking in other conditions (for example, the more rapid reduction seen in $\mathrm{FEV}_{1}$ in cystic fibrosis during puberty). Moreover, physicians who are not aware of the rapid growth rate and alteration of the hepatic and renal metabolism during puberty may underestimate the need for proper medication dosage.

\section{Impact of psychological changes}

Due to the crisis inherent to their maturation process, adolescents are often considered as non-compliant, but such a view must not be generalised. ${ }^{59}$ Adherence to a treatment regimen requires appropriate cognitive capacities and personal organisation as well as a personal belief that the treatment is required and beneficial. ${ }^{60}$ Adherence is maximised when the professional-patient partnership decides management strategies in the light of the health beliefs and personal goals of the patient. ${ }^{6}$

Young people may have difficulty adhering to treatment regimens devised for them by health professionals and parents because of poorly developed abstract thinking, which may manifest as a relatively poor ability to plan and prepare for different situations using abstract concepts; an immature ability to imagine future consequences; and a concept of themselves as "bullet proof" or not vulnerable to the usual rules of life. Together, these cognitive issues may mean that the prevention of long term complications of illness is a poor motivator for compliance. ${ }^{62}$ Additionally, adherence may be impaired because of a lack of shared health beliefs and goals with the young person's treating health professionals or family.

\section{Impact of the socialisation process}

The development of peer relationships and self-image issues (clothes, dress, public behaviours, etc) may be in conflict with the demands of chronic illness treatment regimens or the disability resulting from orthopaedic or neuromuscular defects. The extent to which such adolescent issues affect illness management and control will depend on how young people balance competing priorities. For example, modern diabetes regimens include lunchtime injections, which some young people find unacceptable for reasons of "fitting in" or because they prioritise social time over disease control. ${ }^{63}$ In chronic illnesses where young people may resort to devices or medication for regular treatment and monitoring, decisions about carrying inhalers (asthma or cystic fibrosis), insulin pens or glucometers (diabetes), or other medications may be influenced by how young people balance competing priorities. ${ }^{64}$

\section{Exploratory and health related behaviours}

Adherence and chronic illness control can be put at risk by developmental needs to explore possible modes of future behaviour, usually derogatively referred to as "adolescent risk taking". Chronically ill adolescents show substance use rates similar $^{20}{ }^{65}$ or even higher than their healthy controls. ${ }^{7}$

Similarly, a number of studies have shown that young people with chronic illness and disability are not less likely than peers to be sexually active ${ }^{66}$ and that age of sexual debut, pregnancy involvement, patterns of contraceptive use, or sexual orientation are little different in those with different chronic conditions and the general population. ${ }^{67}$ The visibility of the chronic condition or disability does not appear to affect sexual behaviours in adolescents. ${ }^{67}$

\section{SUMMARY}

Approximately one adolescent out of ten has a chronic condition that somehow limits his or her daily activities. There is substantial evidence that chronic conditions can affect adolescent development and that adolescent development can have an effect on the condition. Adolescence is a time of rapid changes and turmoil. Teenagers with chronic conditions have an additional burden. However, in comparing them to their healthy peers, there seem to be more commonalities than differences. They need the same guidance and prevention as any other adolescent.

\section{Authors' affiliations}

J-C Suris, Groupe de Recherche sur la Santé des Adolescents (GRSA), Institut Universitaire de Médecine Sociale et Préventive (IUMSP), Lausanne, Switzerland

P-A Michaud, Unité Multidisciplinaire pour la Santé des Adolescents (UMSA), Centre Hospitalier Universitaire Vaudois (CHUV), Lausanne, Switzerland

R Viner, Royal Free Hospital \& University College Medical School and Great Ormond St Hospital for Children, London, UK

\section{REFERENCES}

1 Suris J. Global trends of young people with chronic and disabling condition. J Adolesc Health 1995; 17:17-22.

2 Westbrook L, Stein R. Epidemiology of chronic health conditions in adolescents. Adolescent Medicine State of the Art Reviews 1994;5:197-209.

3 Perrin E, Newacheck P, Pless BA. Issues involved in the definition and classification of chronic health conditions. Pediatrics 1993:91:787-93.

4 Newacheck P, Stoddard J. Prevalence and impact of multiple childhood chronic illnesses. J Pediatr 1994;124:40-8.

5 Choquet M, Ledoux S. Adolescents. Enquête nationale: Editions INSERM, 1994.

6 Narring F, Tschumper A, Michaud P, et al. La santé des adolescents en Suisse. Rapport d'une enquête nationale sur la santé et les styles de vie des 15-20 ans. Lausanne, Switzerland: Institut universitaire de médecine sociale ef preventive, 1994.

7 The McCreary Centre Society. Adolescent health survey: chronic illness and disability among youth in B.C. Burnaby, BC: The McCreary Centre Society, 1994.

8 Weiland S, Pless I, Roghmann K. Chronic illness and mental health problems in pediatric practice: results from a survey of primary care providers. Pediatrics 1992;89:445-9.

9 Stein R, Jessop D. A noncategorical approach to chronic childhood illness. Public Health Rep 1982;97:354-62.

10 Stein R, Silver E. Operationalizing a conceptually based noncategorical definition. Arch Pediatr Adolesc Med 1999;153:68-74.

11 Power S, Manor O. Asthma, enuresis, and chronic illness: long term impact on height. Arch Dis Child 1995;73:298-304.

12 Cepeda M, Allen F, Cepeda N, et al. Physical growth, sexual maturation, body image and sickle cell disease. J Natl Med Assoc 2000;92:10-14.

13 Engström I. Inflammatory bowel disease in children and adolescents: mental health and family functioning. J Pediatr Gastroenterol Nutr 1999;28:S28-33.

14 Lavigne J, Gaier-Routman J. Psychological adjustment to pediatric physical disorders: a meta-analytic review. J Pediatr Psychol 1992;17:133-57.

15 Surís J, Parera N, Puig C. Chronic illness and emotional distress in adolescence. J Adolesc Health 1996;19:153-6.

16 LeBlanc L, Goldsmith T, Patel D. Behavioral aspects of chronic illness in children and adolescents. Pediatr Clin North Am 2003;50:859-78.

17 Canning E. Mental disorders in chronically ill children: case identification and parent-child discrepancy. Psychosom Med 1994;56:104-8.

18 Seigel W, Golden N, Gough J, et al. Depression, self-esteem and life events in adolescents with chronic disease. J Adolesc Health Care 1990;1 1:501-4.

19 Jacobson A, Hauser S, Willett J, et al. Psychological adjustment to IDDM: 10year follow-up of an onset cohort of child and adolescent patients. Diabetes Care 1997;20:811-18.

20 Forero R, Bauman A, Young L, et al. Asthma, health behaviors, social adjustment, and psychosomatic symptoms in adolescence. J Asthma 1996;33:157-64

21 Rovet J, Ehrlich R. The effect of hypoglycemic seizures on cognitive function in children with diabetes: a 7-year prospective study. J Pediatr 1999; 134:503-6.

22 Kral M, Brown R, Hynd G. Neuropsychological aspects of pediatric sickle cell disease. Neuropsychol Rev 2001;11:179-96.

23 Hauser S, Jacobson A, Noam G, et al. Ego development and self-image complexity in early adolescence. Longitudinal studies of psychiatric and diabetic patients. Arch Gen Psychiatry 1983;40:325-32.

24 Silver E, Bauman L, Coupey S, et al. Ego development and chronic illness in adolescents. J Pers Soc Psychol 1990;59:305-10.

25 Manworren R. Developmental effects on the adolescent of a temporary ileostomy. J Wound Ostomy Continence Nurs 1996;23:210-17.

26 Officioso A, Salerno M, Bruzzese E, et al. Adolescents with chronic pathology: body image. Minerva Pediatr 2000;52:539-40.

27 Neumark-Sztainer D, Story M, Resnick M, et al. Body dissatisfaction and unhealthy weight-control practices among adolescents with and without chronic illness: a population-based study. Arch Pediatr Adolesc Med $1995 ; 149: 1330-5$. 
28 Choquet M, Du Pasquier F, Manfredi R. Sexual behavior among adolescents reporting chronic conditions: a French national survey. J Adolesc Health 1997;20:62-7.

29 Good A. Informing schools about children's chronic illnesses: parents' opinions. Pediatrics 1991;88:306-11.

30 Hampson S, Skinner T, Hart J, et al. Effects of educational and psychosocial interventions for adolescents with diabetes mellitus: a systematic review. $J$ Health Technol Assess 2002;5(10):1-79.

31 Neuharth-Pritchett S, Getch Y. Asthma and the school teacher: the status of teacher preparedness and training. J Sch Nurs 2001;17:323-8.

32 Sturge C, Garralda M, Boissin M, et al. School attendance and juvenile chronic arthritis. Br J Rheumatol 1997; 1997:1218-23.

33 McCarthy A, Williams J, Eidahl L. Children with chronic conditions: educators' views. J Pediatr Health Care 1996;10:272-9.

34 Westbom L. Well-being of children with chronic illness. A population-based study in a Swedish primary care district. Acta Paediatr 1992;81:625-9.

35 Charlton A, Lacombe I, Meller SA. Absence from school related to cancer and other chronic conditions. Arch Dis Child 1991;66:1217-22.

36 Pless I, Power C, Peckham C. Long-term psychosocial sequelae of chronic physical disorders in childhood. Pediatrics 1993;91:1131-6.

37 Pless I, Cripps H, Davies J, et al. Chronic physical illness in childhood: psychological and social effects in adolescence and adult life. Dev Med Child Neurol 1989:31:746-55.

38 White P. Transition to adulthood. Curr Opin Rheumatol 1999;11:408-11.

39 Cadman D, Rosenbaum P, Boyle M, et al. Children with chronic illness: family and parent demographic characteristics and psychosocial adjustment. Pediatrics 1991;87:884-9.

40 Eiser C, Berrenberg J. Assessing the impact of chronic disease on the relationship between parents and their adolescents. J Psychosom Res 1995;39:109-14

41 Blum $R$, Resnick $M$, Nelson $R$, et al. Family and peer issues among adolescents with spina bifida and cerebral palsy. Pediatrics 1991;88:280-5.

42 Graetz B, Shute R, Sawyer M. An Australian study of adolescents with cystic fibrosis: perceived supportive and nonsupportive behaviors from families and friends and psychological adjustment. J Adolesc Health 2000;26:64-9.

43 Brook U, Tepper I. Self image, coping and familial interaction among asthmatic children and adolescents in Israel. Patient Educ Couns 1997;30: 187-92

44 Engström I. Parental distress and social interaction in families with children with inflammatory bowel disease. J Am Acad Child Adolesc Psychiatry 1991;30:904-12

45 Batshaw M, Perret Y, Trachtenberg S. Caring and coping: the family of a child with disabilities. In: Ym BMP, eds. Children with disabilities. A medical premier. Baltimore: Paul H Brooks Publishing, 1992:563-79.

46 Taanila A, Kokkonen J, Jarvelin M. The long-term effects of children's earlyonset disability on marital relationships. Dev Med Child Neurol 1996:38:567-77.

47 Seltzer M, Greensberg J, Floyd F, et al. Life course impacts of parenting a child with a disability. Am J Ment Retard 2001;106:265-86.

48 Cappelli M, McGarth P, Daniels T, et al. Marital quality of parents of children with spina bifida: a case-comparison study. J Dev Behav Pediatr 1994;15:320-6.

49 Kell R, Kliewer W, Erickson M, et al. Psychological adjustment of adolescents with sickle cell disease: relations with demographic, medical, and family competence variables. J Pediatr Psychol 1998;23:301-12.
50 Drotar D. Relating parent and family functioning to the psychological adjustment of children with chronic health conditions: What have we learned? What do we need to know? J Pediatr Psychol 1997;22:149-65.

51 Ladd G. Peer relationships and social competence during early and middle childhood. Annu Rev Psychol 1999;50:333-59.

52 La Greca A. Peer influences in pediatric chronic illness: an update. J Pediatr Psychol 1992;17:775-84.

53 Shah S, Peat J, Mazurski E, et al. Effect of peer led programmes for asthma education in adolescents: cluster randomised controlled trial. BMJ $2001 ; 322: 583-5$

54 Noll R, Kozlowski K, Gerhardt C, et al. Social, emotional, and behavioral functioning of children with juvenile rheumatoid arthritis. Arthritis Rheum 2000;43: 1387-96

55 Noll R, Gartstein M, Vannatta K, et al. Social, emotional, and behavioral functioning of children with cancer. Pediatrics 1999;103:71-8.

56 Grey M. Interventions for children with diabetes and their families. Annu Rev Nurs Res 2000;18:149-70.

57 Meehan T, Bergen H, Coveney C, et al. Development and evaluation of a training program in peer support for former consumers. Int $J$ Ment Health Nurs 2002; 11:34-9.

58 Moran A, Jacobs DJ, Steinberger J, et al. Association between the insulin resistance of puberty and the insulin-like growth factor-l/growth hormone axis. J Clin Endocrinol Metab 2002;87:4817-20.

59 Alvin P, Rey C, Frappier J. Compliance thérapeutique chez l'adolescent malade chronique [compliance among teenagers with a chronic disease] Arch Pediatr 1995;2:874-82.

60 Vermeire $E$, Hearnshaw $H$, Van Royen $P$, et al. Patient adherence to treatment: three decades of research. A comprehensive review. J Clin Pharm Ther $2001 ; 26: 331-42$.

61 Mullen P. Compliance becomes concordance. BMJ 1997;314:691-2.

62 Kyngäs H, Kroll T, Duffy M. Compliance in adolescents with chronic diseases: a review. J Adolesc Health 2000;26:379-88.

63 Swift P. Optimization of insulin treatment in children. Ann Med 1997;29:419-24.

64 O'Callaghan C, Barry P. How to choose delivery devices for asthma. Arch Dis Child 2000;82:185-7.

65 Alderman E, Lauby J, Coupey S. Problem behaviors in inner-city adolescents with chronic illness. J Dev Behav Pediatr 1995;16:339-44.

66 Blum R. Sexual health contraceptive needs of adolescents with chronic conditions. Arch Pediatr Adolesc Med 1997;151:290-7.

67 Suris J, Resnick M, Cassuto N, et al. Sexual behavior of adolescents with chronic disease and disability. J Adolesc Health 1996;19:124-31.

68 Alvin P, Marcelli D. Les maladies chroniques: enjeux physiques et psychiques. In: Michaud P, Alvin P, et al. La santé des adolescents: approches soins prévention. Lausanne, Paris, Montréal: Payot, Doin, PUM, 1997:185-98.

69 Schowalter J. Psychological reactions to physical illness and hospitalization in adolescence: a survey. J Am Acad Child Psychiatry 1977;16:500-16.

70 Nicasio M, Smith T. Managing chronic illness: a biopsychosocial perspective. Washington, DC: American Psychological Association, 1995.

71 Strax T. Psychological issues faced by adolescents and young adults with disabilities. Pediatric Annals 1991;20:507-11.

72 Weekes D. Adolescents growing up chronically ill: a life-span developmental view. Fam Community Health 1995;17:22-34 